This item was submitted to Loughborough's Research Repository by the author.

Items in Figshare are protected by copyright, with all rights reserved, unless otherwise indicated.

\title{
Elevating the human experience (HX) through service research collaborations: introducing ServCollab
}

PLEASE CITE THE PUBLISHED VERSION

https://doi.org/10.1108/JOSM-10-2019-0325

\section{PUBLISHER}

Emerald Publishing Limited

\section{VERSION}

AM (Accepted Manuscript)

\section{PUBLISHER STATEMENT}

This paper was accepted for publication in the journal Journal of Service Management and the definitive published version is available at https://doi.org/10.1108/JOSM-10-2019-0325.

\section{LICENCE}

CC BY-NC-ND 4.0

\section{REPOSITORY RECORD}

Fisk, Raymond P., Linda Alkire, Laurel Anderson, David E. Bowen, Thorsten Gruber, Amy L. Ostrom, and Lia Patrício. 2020. "Elevating the Human Experience (HX) Through Service Research Collaborations: Introducing Servcollab". Loughborough University. https://hdl.handle.net/2134/12116316.v1. 


\section{Elevating the Human Experience (HX) Through Service Research Collaborations: Introducing ServCollab}

\begin{tabular}{|r|l|}
\hline Journal: & Journal of Service Management \\
\hline Manuscript ID & JOSM-10-2019-0325.R1 \\
\hline Manuscript Type: & Research Paper \\
\hline Keywords: & $\begin{array}{l}\text { Wellbeing, human experience, service design, transformative service } \\
\text { research, service inclusion }\end{array}$ \\
\hline \multicolumn{2}{|l}{} \\
\hline
\end{tabular}

\section{SCHOLARONE ${ }^{\mathrm{m}}$ \\ Manuscripts}




\title{
Elevating the Human Experience (HX) Through Service Research Collaborations: Introducing ServCollab
}

\begin{abstract}
Purpose:

Elevating the human experience (HX) through research collaborations is the purpose of this article. ServCollab facilitates and supports service research collaborations that seek to reduce human suffering and improve human wellbeing.

\section{Design/methodology/approach:}

To catalyze this initiative, we introduce ServCollab's three human rights goals (serve, enable, and transform), standards of justice for serving humanity (distributive, procedural, and interactional justice), and research approaches for serving humanity (service design and community action research).
\end{abstract}

\section{Research implications:}

ServCollab seeks to advance the service research field via large-scale service research projects that pursue theory-building, research, and action. Service inclusion is the first focus of ServCollab and is illustrated through two projects (transformative refugee services and virtual assistants in social care). This paper seeks to encourage collaboration in more large-scale service research projects that elevate the Human Experience (HX).

\section{Practical implications:}

ServCollab seeks to raise the aspirations of service researchers, expand the skills of service research teams, and build mutually collaborative service research approaches that transform human lives. 


\section{Originality/value:}

ServCollab is a unique organization within the burgeoning service research community. By collaborating with service researchers, with service research centers, with universities, with nonprofit agencies, and with foundations, ServCollab will build research capacity to address large-scale human service system problems. ServCollab takes a broad perspective for serving humanity by focusing on the human experience (HX). Current business research focuses on the interactive roles of customer experience and employee experience. From the perspective of HX, such role labels are insufficient concepts for the full spectrum of human life.

Keywords: Wellbeing, human experience, service design, transformative service research, vulnerable consumers, service inclusion, collaboration

Paper type: Viewpoint 


\section{Elevating the Human Experience (HX) Through Service Research Collaborations: Introducing ServCollab}

\section{Introduction}

As the service research field has evolved, our understanding of the nature of service has shifted from being peripheral to human experience to becoming central to human experience. One aspect of this new centrality of service has been the expansion of research topics beyond dyadic service encounters (Bitner et al., 1990) to service systems (Maglio et al., 2009) and then to service ecosystems (Akaka and Vargo, 2015). A second aspect is the emergence of the Transformative Service Research (TSR) movement, which has raised the aspirations of the service research field to improving human wellbeing (Anderson et al., 2013) and reducing its suffering (Nasr and Fisk, 2019). There is great power and potential in this new understanding of the central role of service in human life. Fundamentally, the centrality of service to human experience means that the greatest potential of the service research field is yet to be explored and discovered. ServCollab was created to enable the service research field to elevate human experience $(\mathrm{HX})$ through service research collaborations.

\section{Why Now? Advancing the Service Research Field}

As scientific inquiry has become increasingly complex, some scientific fields have created what have been called "big science" projects. Such projects began in the physical sciences with projects like the Manhattan Project, which produced the first nuclear weapons. In most cases, such projects have been government funded. In the life sciences, the largest project was the Human Genome Project, which mapped the genes of the human genome. Such big science projects have required large scientific teams, sophisticated technology, and large budgets. For the service research field to make major scientific advances and truly improve 
human wellbeing and reduce its suffering, it will require larger service research projects. Such projects will require that service researchers build large and inclusive project teams, sharpen their collaboration skills, and hone their research tools for serving humanity. It will also require that service researchers create and share a service language that improves communication across the service research community (Fisk and Grove, 2010). Most importantly, it will require that service researchers develop service standards for properly serving humanity.

\section{What Is ServCollab?}

ServCollab is a service research organization for diagnosing and treating humanity's service system problems (poverty, ignorance, disease, etc.). For instance, failure of educational and healthcare systems, which are some of the biggest service industries in any country, results in the propagation of poverty, sickness, and decreased quality of life among many other negative societal implications. As an independent and unfettered entity, ServCollab seeks to transform the service research community by enabling collaborative solutions to profound human service system problems. In addition to taking on large scale service research projects, ServCollab will practice collaboration in its operations, help train others in collaborating on large scale service research projects, foster best practices for collaborative teams, and serve as a clearinghouse for collaborative service research resources.

To serve humanity, ServCollab seeks to elevate the human experience (HX), which is our holistic concept for the totality of each person's experience with service systems as they seek to meet their basic human needs across their life journey. HX focuses fully on each person's life rather than on the various specific service roles they might enact at specific times. Thus, it is both broader and deeper than the specific role-based concepts of customer experience (CX), user experience (UX), or employee experience (EX). 
There are numerous existing academic service organizations that address research. These include service centers at various universities, service conferences, and the American Marketing Service Special Interest Group (SERVSIG). ServCollab will seek collaborative activities with these academic service organizations and their members. With the help of the experience, expertise, and connections of such academic participants, ServCollab can elevate HX.

\section{Why Focus on Collaboration?}

As a social species, human interactions are learned behaviors that are essential for human existence. Table 1 shows our conceptualization of four categories of human interaction: conflict, competition, cooperation, and collaboration. Conflict and competition are common interactions that are chronicled widely in human history. Conflict starts as an argument but can escalate into a war. Competition refers to seeking the same resources through a rules-based contest. Both conflict and competition result in winners seeking dominance over the losers. Such dominance is associated with the origination of the word service. Service is derived from the Latin word "servus" (Merriam-Webster.com 2020), which means slave or servant.

Place Table 1 about here

Cooperation and collaboration have been less prominently chronicled by historians. Cooperation is participatory interaction but not always voluntary interaction. Cooperation can be coerced by law, by bullying, or by physical force. As such, cooperation can lead to unequal and unjust outcomes whereas one party could be benefiting at the expense of the other. Collaboration is distinguished by shared intentionality (Angus and Newton 2015). Collaborative interactions 
occur when people eagerly engage in working with each other. Anthropologists (Tomasello et al., 2012) have characterized the evolution of our species in prehistoric times as mutualistic collaboration driven by interdependence. Such mutualistic collaboration began with the first service systems (families) and continued with the steady evolution in sophistication of human service systems from families, to tribes, to villages, to cities, and to nations (Fisk, 2009; Fisk and Grove 2010).

Our species evolved to be great at small-scale collaboration in families, tribes, and villages (Tomasello et al., 2012), but we struggle with unfairness problems in the large-scale complexity of cities and nations. Complexity makes it more challenging to reach agreement and easier to disagree. New human collaboration innovations are needed to overcome the modern human challenges of more than 7 billion people competing for resources on Planet Earth.

Daniel Dennett (1995) proposed the metaphor of a "crane" to explain Darwin's concept of natural selection. He argues that language and culture are cranes that provide the basis for structures of greater complexity. "Human culture, as we have already seen, is not just a crane composed of cranes, but a crane-making crane." (Dennett, 1995, Chapter 12-The Cranes of Culture). Languages, cultures, arts, education, and science are all collaborative service system cranes. Further, collaboration is essential for elevating human experience (HX). ServCollab seeks to build a collaborative service research crane to help service researchers elevate HX (see Figure 1).

Place Figure 1 about here 
ServCollab seeks to practice and propagate collaborative service research. More specifically, ServCollab will seek to practice transformative collaboration (Fisk et al. 2019):

"Transformative collaboration occurs when all participants are able to make contributions at their full human potential." (p. 198). ServCollab will pursue transformative collaboration through service research projects that reduce violations of human rights and enable more sustainable and satisfying HX. We believe that with this elevated HX perspective, those we serve will have better human experiences in their specific service roles as parents, citizens, customers, employees, etc.

ServCollab's Mission

ServCollab's mission is "to serve humanity through service research collaborations that catalyze reducing human suffering and improving human wellbeing." These service research collaborations will elevate HX by pursuing ServCollab's three human rights goals: serve, enable, and transform.

ServCollab's Human Rights Goals

To develop ServCollab's goals, we adopt a process view starting with the need to "serve," followed by "enabling," with the ultimate goal of "transforming":

1. Serve - ServCollab seeks to serve all humans with research that respects their dignity and supports their rights. This includes advocating for fair and inclusive service experiences starting with fair and inclusive access to service, fair and inclusive service encounters, and fair and inclusive ability to exit the service.

2. Enable - ServCollab seeks: 1) to enable collaborations among researchers and organizations that span disciplinary and national boundaries in pursuit of diagnosing and treating humanity's many service system problems, 2) to enable access to the human and financial 
resources necessary for the success of such collaborations, 3) to enable a deeper understanding of service systems, and 4) to propagate a humane design science for service systems.

3. Transform - ServCollab seeks transformative reductions in human suffering and transformative improvements in human wellbeing. Further, ServCollab seeks: 1) to measure both the quantities and qualities of service systems, 2) to foster standards of service that are adaptable and measurable across different service systems, and 3) to evolve those service standards to better fulfill human potential.

To elaborate on the foundational perspectives and concepts that form the basis for ServCollab, we begin by exploring a broader perspective on serving humanity. The second section proposes standards of justice for serving humanity. The third section considers the role of TSR in raising our aspirations for serving humanity. The fourth section explores powerful research approaches for serving humanity. The fifth section summarizes ServCollab's first projects on service inclusion. The sixth section discusses a call to collaborate on future ServCollab efforts.

\section{Human Experience (HX): A Broader Perspective on Serving Humanity}

When Vargo and Lusch (2004) introduced Service-Dominant Logic (S-D logic) it was a key milestone in the broadening of thinking about service. They argued that service is fundamental to all economic and social exchange. This launched many service researchers on a path of rethinking the foundations of the service research field, which included expanding from the original focus on service encounters (Bitner et al., 1990) to service systems (Maglio et al., 2009) and then to service ecosystems (Akaka and Vargo, 2015; Lusch and Vargo 2014). 
ServCollab takes a broader perspective for serving humanity by focusing on the human experience (HX). Current business terminology labels people's primary interactive roles in service systems as customer and employee. From the perspective of HX, such specific interaction role labels are insufficient concepts for the full richness of human life. Customer Experience (CX) and Employee Experience (EX) have been the subjects of considerable research effort but CX and EX are just parts of each person's overall human experience.

HX is broader and deeper, as people seek to gratify their basic human needs. Schneider and Bowen (1995) contrasted the perspective of customer expectations versus customer needs. Customer expectations are concerned with “Desired outcomes from service encounters." In contrast, customer needs are concerned with "Desired outcomes from human existence." Although expectations and needs fall on a continuum, they are very different lenses on human experiences. Additionally, violations of expectations yield disappointment or dissatisfaction, but violation of basic human needs result in anger and outrage. Schneider and Bowen (1995) proposed three basic human needs: security, esteem, and justice, as particularly relevant to server-served exchange. Security and esteem were drawn from a synthesis of needs from Maslow's (1943) hierarchy of needs. They added justice since as long ago as Aristotle it has been recognized that a moral sense is basic to being human, and people hold on to a belief that they should get what they deserve. They believe they should live in a just world. HX should be the focus of future service research. It will require building a new service language for understanding and serving human needs. One challenge will be how to conceptualize and name outcomes at higher levels than service roles such as customer and employee.

The need for justice will be our primary focus in elevating HX through service research collaborations via ServCollab. The need for justice reflects peoples' yearning to feel that they 
live in a "just world" (Scheider \& Bowen,1995). Living in conditions that violate their need for security and being treated in demeaning ways that violate their sense of self-esteem certainly compromise belief that they live in a just world. Next, we describe a framework that can help guide action and research on how to deliver three types of justice for people.

\section{Standards of Justice for Serving Humanity}

Service systems are created by humans for humans, but they do not always meet human needs fairly. Rawls conceptualized justice as fairness (1999). Fairness requires just service systems institutions. The concept of justice refers to peoples' sense of the moral propriety of how they are treated. Justice includes the moral obligations that each party has to the other.

Cropanzano et al. (2007) elaborated three types of justice for employees, customers, and people overall: distributive, procedural, and interactional.

\section{Distributive Justice}

Distributive justice refers to the perceived fairness of the outcomes received from a service system. According to Deutsch (1985), distributive justice issues are abundant throughout society as they exist in all situations where people enter into exchanges, thus it has direct relevance to service. The concept of distributive justice originates from social exchange theory (Blau, 1964; Adams, 1965), which emphasizes the role of equity in shaping subsequent exchanges. Three basic distributive justice principles, or distributive rules, are equity, equality, and need (see Deutsch, 1985; Tyler, 1994). The outcomes from the service system might be allocated based on equity (each person's contributions), equality (each person receives roughly the same), or need (based on each person's requirements). Messick and Cook (1983) explain equity in light of fair exchanges based on one's contribution to the exchange (Deutsch, 1985). 
Despite the pervasive nature of this approach, (1) individual's needs and (2) equality regardless of one's contribution have been introduced as essential for distributive justice understanding and implementation. According to Blodgett et al. (1997), most marketing studies have focused almost solely on equity (i.e. fairness based on contribution) as the appropriate distributive rule.

ServCollab seek to extend the focus on individual needs and equality beyond individual contribution given that different people have different needs and resources that they bring to the exchange. Many of these needs and resources are not proportional to the outcomes they are seeking and deserve. Within various service systems such as education and healthcare, we witness the lack of distributive justice. Some recipients require more attention or resources than the general public to be able to achieve their potential. As such, individual needs and equality should be emphasized throughout their service experiences.

\section{Procedural Justice}

Procedural justice refers to the perceived fairness in the allocation process (i.e., policies, procedures, criteria) governing decisions involving treatment and benefits in service systems. According to Leventhal et al. (1980), fair process should be consistent, unbiased, and impartial; inclusive of all parties' interests; and based on accurate information and on ethical standards. As such, when procedural justice occurs, no group is singled out for discrimination or ill-treatment, decisions are based on accurate information, appeal processes are possible, ethics are not violated, and the appropriate stakeholders have input into decisions. ServCollab seeks to highlight the importance of fair service procedures that guarantee procedural justice to all involved parties.

Interactional Justice 
Interactional justice refers to the perceived fairness of the interpersonal treatment (i.e. respect, courtesy, honesty, empathy) one receives from others during a service encounter. This can take an informational form of sharing relevant information or the interpersonal form of being treated with dignity, courtesy, and respect. Interactional justice focuses on the two-way interactions including the way in which people are treated with respect, interest, friendliness, honesty, and politeness (Lacey and Sneath, 2006). Overall, there are two types of interactional justice (Colquitt et al., 2001). First, interpersonal justice relates to the respect and dignity with which one treats another. Second, informational justice means to be truthful and to provide justifications when things go badly. Fairness is achieved when people are treated with dignity, respect and politeness (Kabadayi et al., 2019). While procedural justice focuses on the formal aspect of the service process, interactional justice emphasizes the social aspect of the process (Skarlicki and Folger, 1997). As such, even if an individual perceives the outcomes and procedures of a service as reasonable or satisfactory, they may still feel mistreated if they discern unfair status treatment during a service encounter. ServCollab seeks to highlight the importance of human values such as respect, empathy, compassion, friendliness, honesty, and politeness within services exchanges and to prevent myopic procedures and outcomes.

Cropanzano et al. (2007) note the challenge of maintaining all three types simultaneously and offer that the ill effects of injustice can be reduced if at least one type of justice is maintained. For example, distributive and procedural injustice will have less negative effect if interactional justice is high. ServCollab advocates considering all three types of justice as essential for improving human wellbeing and reducing its suffering.

\section{Raising Our Aspirations for Serving Humanity}


The Transformative Service Research (TSR) movement has raised aspirations by advocating service research that attends to improving human wellbeing. TSR has been defined as research that focuses on creating "uplifting changes aimed at improving the lives of individuals (both consumers and employees), families, communities, society, and the ecosystem more broadly" (Anderson and Ostrom, 2015, p. 243). At its core, TSR focuses research attention on people (collective and individual) and aspects of service that affect the nature of their experience as humans in order to reduce human suffering and improve wellbeing.

As we consider TSR and ServCollab's large-scale mission of reducing human suffering and improving wellbeing, it is especially important to build more consideration of macro elements such as service systems and ecosystems. There have been previous calls for more transformative service emphasis and recognition of the collective levels of humans and the structural aspects of services (Anderson and Ostrom, 2015), but the focus on individual consumers and dyads still overshadows more macro elements.

Three illustrative conceptual pathways might be helpful in moving Transformative Service Research and ServCollab projects to macro elements: capability (Sen, 1982), social quality (Abbott and Wallace, 2012), and symbolic boundaries (Lamont et al., 2015). This is far from a comprehensive list of helpful theories, but each of these theoretical perspectives gives rise to the gnarly question regarding where the responsibility for defining and accomplishing wellbeing lies and recognizes the often ignored influence of structures - in particular, the structures that services in their ubiquity create (Anderson and Ostrom, 2018). Structures are recurring arrangements that influence and limit the opportunities that are available to social groups (Barker, 2005). 
Capability. The capability approach was initiated by economist Amartya Sen (1982). It was unique at the time in that it introduced an ethical social justice component. Capability raises the question of the availability of means to and opportunities for a good life and wellbeing. Capabilities are the effective freedoms or valuable opportunities from which humans can choose in terms of different kinds of life that they value and want to experience (Robeyns, 2016). These opportunities are made feasible and constrained by external (social, structural, and environmental) as well as internal factors such as experiences and motivations (Crocker, 2008). Since services are so ubiquitous, the structures that are created by services can both create and restrict capabilities. For example, some housing services for the aging, such as many nursing homes, restrict choices regarding movement, food, schedule, companionship, etc. Whereas other service structures and initiatives such as aging in community efforts seek to increase choices on these aspects (Thomas and Blanchard, 2009). Services define, in part, what human experiences and capabilities are available or absent to humans. This raises important questions for TSR and ServCollab. For example, consider these questions for someone with vision challenges or someone in a refugee camp. What are the ways that service systems structure capabilities? How are capability decisions made in services? How much collaboration is occurring in this structuring? How does this collaboration vary with different groups? When and how is capability restriction most likely to happen? How can these restrictions be avoided? What is critical for service systems to identify in the ways they structure capabilities? How can services help convert capabilities to valued human experience? What capabilities might be systemically limited or privileged for certain groups by service structures?

Social Quality. Social Quality theory digs deeper into which structural aspects maximize collective wellbeing (Abbott and Wallace, 2012) and thus can provide assistance in developing 
standards of care for properly serving humanity. The Social Quality model is a multidimensional construct where society is envisaged as the results of social and systems integration that then provides the context for human agency (Giddens, 1984). Social Quality forefronts those aspects of social structures that enable humans to flourish. The most well-known model identifies four fields: economic security, social cohesion, social inclusion, and the conditions for social empowerment (Lockwood, 1992). The Social Determinants of Health framework is an example of a social quality model focused specifically on health wellbeing and includes positions on the social gradient, stress, early life, social exclusion, work, unemployment, social support, addiction, food, and transport (Wilkinson and Marmot, 2003). This theory and research suggest wider responsibility for creating healthy societies and suggests that services should take proper account of these dimensions. How can service systems support and grow factors that impact collective wellbeing? Recent work by Waygood et al. (2019) highlights not only the wellbeing impact that different types of transportation have on children, but what different types of activities are enabled or restricted by transportation. Research questions can revolve around how these different social qualities are taken into account in and created by service structures.

Symbolic Boundaries. ServCollab advocates for fair and inclusive service experiences starting with fair and inclusive access to service, fair and exclusive service encounters as well as fair and inclusive exit from the service. Symbolic Boundaries theory provides a conceptualization useful in realizing this goal. Symbolic Boundaries are conceptual tools that people use to understand the world in terms of the lines that include and define some people, groups, and things while excluding others (Lamont and Molnar 2002). These distinctions can be communicated through taboos, cultural attitudes and practices, and patterns of likes and dislikes (Lamont et al., 2015). Service structures and programs draw boundaries. As Edgell et al. (2019) 
point out, this is not a benign activity. For example, research has found that programs meant to facilitate immigrants' entry into a society may actually emphasize the boundaries that separate them from the national community (Onasch, 2017). It seems that there are overt, planned boundaries (e.g., a certain age for the purchase of alcohol) and there are more covert boundaries (e.g., systemic restricted choice of minorities seeking financing (Bone et al., 2014)). Symbolic Boundaries theory raises TSR questions such as: Can services avoid drawing boundaries? How do service structures construct and communicate these boundaries? How can service structures approach boundaries in a way that is not destructive? What trade-offs occur with boundaries in services? What elements of service structures are most fair and inclusive? With regard to services and boundaries, what developmental or situational times are most critical in impacting wellbeing?

All of these theoretical approaches recognize the impact that service structures and systems may have on wellbeing. Assuming that an individual is solely responsible for their wellbeing while ignoring the impact of structures runs the risk of decreasing collective and individual wellbeing, or at the very least, losing opportunities to transform wellbeing. ServCollab seeks to adopt the TSR aspirations of moving the focus from micro to macro elements. As such, it seeks to support research projects that address higher-level questions focused on improving wellbeing and reducing suffering.

\section{Research Approaches for Serving Humanity}

In this section, ServCollab advocates two research approaches for serving humanity - service design and action research.

Designing new service solutions to serve humanity 
Service design can be defined as a human-centered, holistic, creative, and iterative approach to service innovation (Meroni and Sangiorgi, 2011), rooted in design as changing existing situations into preferred futures (Simon, 1969). Service design integrates S-D logic with design approaches and tools to envision future service systems and new forms of value cocreation (Wetter-Edman et al., 2014) that align with the human rights goals of ServCollab. These design roots mean that service design is action-oriented towards developing new service solutions to meet needs and improve situations (Friedman, 2003).

Service design research can leverage explanatory research, which focuses on understanding service systems, by complementing it with action-oriented design research for system transformation through service (Patrício et al., 2019). To this end, design science offers a research approach that goes beyond creating concrete new services to developing theoretically grounded and empirically tested solutions for more general classes of problems (Van Aken, 2004). Design science research can therefore support service design research (Teixeira et al., 2019), especially in developing new methods and principles that move beyond the design of dyadic service interactions for the customer experience, to the design of services as transformative enablers of value co-creation for wellbeing and the Human Experience as a whole. Service design, therefore, offers important tools and opportunities to ServCollab for developing solutions for problems to better serve humanity.

Designing for and with people to enable balanced and mutual value co-creation. Addressing key problems of human service systems such as poverty or chronic diseases requires dealing with a high level of complexity given the multitude of actors involved with different perspectives and goals, linked by a complex web of co-creating interactions, and enabled and constrained by institutions. Service design adopts a participatory, democratic process focused on developing 
knowledge that can improve the wellbeing of individuals and communities (Sangiorgi, 2010).

Service design takes a human-centered and participatory approach, designing for and with people, and can contribute to creating balanced solutions to uplift human service systems. Designing for people involves a sensemaking approach, viewed as a social construction of meaning focused on understanding how people experience and understand the world around them, and reflecting this sensemaking in the solutions being developed (Cipolla and Reynoso, 2017). Designing with people reflects a participatory approach where people are considered true experts in domains of experience such as living or working, and as such they are actively involved as co-creators in the design process, while the designer plays a facilitator role (Sanders, 2008). This participatory approach is particularly important in complex contexts such as healthcare to understand and bring different actors' perspectives (e.g. patients and healthcare practitioners) into a collective sensemaking design process, mapping their interactions and potential conflicts, collaboratively developing balanced service solutions for the different actors, and for uplifting the service system as a whole (Patrício et al., 2018b).

Designing service for transformation. The action oriented and participatory approach to service design can also generate transformative value for uplifting changes in individual and collective wellbeing (Blocker and Barrios, 2015). This transformative service design approach seeks to create, not only new service solutions, but also the platforms and capacities for ongoing and lasting change (Sangiorgi et al., 2019). Service design can, therefore, promote the change of ingrained norms, rules, and beliefs of different system actors, such as fostering more humancentered and participatory approaches in healthcare, and promoting ecosystem innovation through institutional change (Vink et al., 2019). For example, by using design methods to stage situations and propose environments that question healthcare professionals' assumptions and 
habits, service design can create aesthetic disruptions to change the way they see and interact with patients (Wetter-Edman et al., 2018).

To integrate the transformative practices of service design, Sangiorgi (2010) proposes a set of transformational principles: 1) active citizens: understanding citizens as 'agents' and their active role as co-creators of wellbeing, 2) Intervention at community scale: focusing on communities as the unit of intervention as they have the right size to activate large-scale changes, 3) Building capacities and research partnerships: building capacities and partnerships through on-going dialogues, which requires changes in organizational culture, but also developing the skills for citizens to participate effectively, 4) Re-distributing power: promoting citizen power in the design process to enhance their skills and capacities to contribute, 5) Enhancing imagination and hope: leveraging design creative process to empower communities to envision new better futures, 6) building infrastructures and enabling platforms for continuous redesign and cocreation, and 7) Evaluating success and impact: namely in terms of outcome validity, democratic validity, process validity, catalytic validity, and dialogical validity.

Service design can make key contributions towards more humane service systems and help ServCollab projects reach their objectives. Its participatory action research and transformative approach can support the design of service systems that are more human and socially inclusive for the common good of humanity (Fisk et al., 2018; Patrício et al., 2018a). Action Research

Action research seeks transformative change through simultaneously conducting research and seeking action. There are different types of action research, but most are enacted through an explicit set of social values that align with the principles of ServCollab. These values translate into a process of inquiry with the following characteristics: 
- "Democratic - enabling the participation of all people.

- Equitable - acknowledging people's equality of worth.

- Liberating - providing freedom from oppressive, debilitating conditions.

- Life enhancing - enabling the expression of people's full human potential." (Stringer, 1999, pp. 9-10).

Critical Participatory Action Research (Critical PAR) is an especially fitting type of action research, which Michelle Fine describes in her appropriately titled book, Just Research in Contentious Times: Widening the Methodological Imagination (2018a). Critical PAR is research focused on achieving justice and thus starts with the critical part - situating each of the research problems within an analysis of the dynamics producing the problems: power, privilege, disadvantage, structure, and history. This crucial aspect is what Weis and Fine (2012) call critical bifocality which seeks to make visible the linkages through which structural conditions are encoded in policies as well as woven into communities and lives. They fear that "Isolated studies of individuals, cultures, or community life white out structures, histories, and cumulative state neglect; camouflage circuits of disinvestment; and simultaneously fail to reveal the production and reproduction of privilege" (Weis and Fine, 2012, p. 176). To understand the problem, the bifocal lens brings these structures (to include history) and lived practices to the forefront.

Action research subscribes to all of the rigorous methods and theoretical generalizability of traditional research but adds three additional components. First, the research is collaborative. The perspectives of those most impacted by the research problem are central to shaping the research question, method, and research output. At times, the research is even initiated by this group. For example, the Morris Justice Project of the City University of New York's was initiated by mothers of the South Bronx who were concerned with how the New York Police 
Department (NYPD) treated their sons. Soon, a collaborative research team formed. This team met weekly on Morris Avenue to brainstorm, design the research, analyze, and plan for action (Morris Justice). Second, the research results are given back to the community and metabolized into materials for policy change, popular education, and targeted dispersion. These materials and communications might take many forms including the public performance of the data. For example, the same Morris Justice project wrote a letter to the NYPD and projected this letter onto buildings in the Bronx (Fine, 2018b). Others, such as von Koskull's work with the elderly uses ethnodrama (von Koskull and Anderson, 2018) to communicate their findings to the public, policy makers, managers, and the community. And lastly, especially with Critical PAR, radical alternatives to current practices are generated and action is taken. For example, the Morris Justice Project involved the community through community safety walls where the community was asked to discuss what community safety meant to them. Seven categories of thinking arose from these efforts. This led to support of the Community Safety Act (Goodman, 2013). As mentioned in previous discussion of action research (Ozanne and Anderson, 2010), academic researchers have certain expertise and are involved to varying degrees with these different aspects of the research. Recognizing multiple forms of expertise, the academic researcher is a humbler part of the action research process than in more traditional research.

Even in its name, action research explicitly seeks an impact. It has impact on the ground where collaborative relationships create solidarity in the materials that are developed for popular and targeted education within the community; in the policy change work done through papers, videos, meetings, etc.; and in academic publications (Fine, 2018b). And while action research has so many benefits as far as impact, Critical PAR is not for the faint of heart researcher. It is complex, requires transparency, and often presents ethical questions that are not clear-cut. Some 
of the ethical questions arise from any type of highly involved research whereas others are unique to action research. These are just a few of the ethical dilemmas for Critical PAR:

- Privacy - How do you maintain individual privacy when the data is presented back to the community and the work is collaborative? How do you maintain community privacy when action (often policy action) is the desired end?

- Sustainability - How is the action sustained after the researchers leave the community or the grant expires? "Helicopter and parachute research refer to the practice of academic researchers inserting themselves into vulnerable communities to collect data, and abruptly leaving without returning findings to, or meaningfully impacting the lives of intended and unintended participants. Mosquito research is a term coined by Indigenous peoples in North Carolina; it names the tendency of graduate student researchers seeking to conduct research over the summer months. Researchers are likened to mosquitos, to an ephemeral, pestering, and disruptive presence - that leaves bites and wounds that take time to heal." (Guishard et al., 2018).

- Presentation - If presentation of the research results is meant to persuade and are collaborative, do you change quotes or parts of the communication to be more "professional”? Which of the collaborators' voices do you use? (Guishard et al., 2018).

- "Damage-centered" research - Through good intentioned advocating for action, reallocation, and change, a one-sided view of the community as drained, depleted, and helpless may be unintentionally presented. This can perpetuate the perception of the inferiority of the community and reduce perceptions of viable options and actions (Tuck, 2009). 
- Vicarious trauma - Secondary trauma can occur to counselors, service providers, attorneys, researchers, and others who, through engagement with traumatized humans, are repeatedly exposed to suffering (van der Merwe and Hunt, 2019).

Community Advisory Boards (CAB) can provide a moral compass for some of the ethical dilemmas and issues raised by Critical PAR. CABs can be created for specific projects or they can become permanent entities for certain communities. CABs can assess risks and benefits to the community of study participation; power between community, academic, and other collaborators; ownership of data; authorship; transparency; accountability; use of findings and by whom; among other issues (Guishard, 2015).

ServCollab seeks to support projects adopting service design and Critical PAR as research approaches. This support includes sharing expertise, organizing workshops, searching for funding, research access, following responsible research standards, and avoiding research pitfalls.

\section{ServCollab Projects}

As mentioned in the research approaches section, ServCollab encourages and supports the formation of large-scale service research projects. The first project area is service inclusion. Service Inclusion

Service inclusion is ServCollab's first project area because a lack of inclusion is at the root and core of unjust human service systems. In response to the pervasive unfairness within service interactions (e.g., systemic bias, customer vulnerability, marketplace discrimination, among others), Fisk et al. (2018) advance the concept of service inclusion as "an egalitarian system that provides customers with fair access to a service, fair treatment during a service, and 
fair opportunity to exit a service.” (p. 835). There is significant evidence that nation states are more successful when they are more inclusive (Acemoglu and Robinson, 2012). Hence, humane service systems should be designed for inclusion (Fisk et al., 2018; Kabadayi et al., 2019). To clarify, inclusion is the process of lifting the excluded up, not bringing anyone down. Inclusion is centered around enabling four major pillars of service inclusion (Fisk et al., 2018): enabling opportunity, offering choice, relieving suffering, and fostering happiness. First, the "Enabling Opportunity" pillar refers to "empowering people by providing access to services and the ability to receive and co-create valued services" (p. 843). The "Offering Choice" pillar stresses the right of people to make a viable choice between different offerings as well as the right to opt out of a particular service/interaction. The "Relieving Suffering" pillar highlights the importance of fulfilling basic human needs in diverse service interactions. Finally, "Fostering Happiness" stresses the importance of pleasure and positive interactions between actors during service exchanges.

Service inclusion problems are commonplace worldwide and many service research projects are needed that seek solutions to exclusionary service systems. ServCollab has encouraged two projects that are service research collaborations on service inclusion: refugee services and virtual assistants in social care services.

Transformative Refugee Services. The first ServCollab service inclusion project calls for rethinking service provisions for refugees to create more hospitable rather than hostile service systems and improving the experiences for refugees with both short term and long-term solutions. Drawing on multidisciplinary expertise that encompasses marketing, sociology, and service science, the researchers seek to assist service scholars, nonprofit service providers, private service providers, and policymakers in transforming refugee lives by navigating the 
challenges prior to, during, and after a refugee's journey (Boenigk et al. 2020). The project will be useful to identify, evaluate, and implement new service-based solutions for refugees at different levels during different phases of refugees' journey.

What is unique about this project is that it truly embodies the aspirations of ServCollab. This project was conducted by an eclectic and multidisciplinary team of academics, research associates, and practitioners with training and experience in different disciplines ranging from public policy, marketing, services, management, and social marketing. In terms of residence, the authors in this group live in seven different countries (Australia, Columbia, Germany, New Zealand, Switzerland, UK, and USA), and in terms of their origins of nationality they represent eight countries (Australia, Brazil, Germany, India, Lebanon, Romania, Turkey, and USA). One common denominator of this diverse group of individuals is their interest in the global refugee crisis and how individuals, organizations, and public policymakers can help alleviate the suffering and improve the wellbeing of those refugees. Therefore, this project was a collaborative effort of a passionate group of individuals that uniquely integrates their different personal backgrounds, professional experiences, and expertise on this very important topic.

Virtual Assistants in Social Care. The second ServCollab service inclusion project explores how disabled people can adapt existing everyday technologies, such as virtual assistants, to help them meet their complex social care needs. Social care supports people who need assistance with their daily living. It consists of a complex system of both private and public services and many communities and families also provide unpaid care. Social care includes several activities across the whole lifecycle: from child protection, helping people with disabilities with taking their medicine and with personal hygiene to end-of-life care (Wilson and Kenny, 2018). 
This second ServCollab project focuses on existing everyday technologies such as virtual assistants that are pre-installed in smartphones (e.g., "Siri" on Apple's iPhone or "Google Assistant" on Android phones) or are embedded in smart speakers and hubs (e.g., "Alexa" in Amazon's Echo (Dot) and Echo Show). Virtual assistants are software programs that listen for keywords to start them up. These keywords are sent to a server and interpreted as a command. The server then provides the voice assistant with information to be read back to the user or to complete requested tasks, such as for example switching on lights or other devices, making phone calls, reading out emails, etc. (Hoy, 2018). Currently, there is only limited knowledge on the use of virtual assistants in social care services. To address the surprisingly limited information on the usage of everyday technologies in social care services, this ServCollab project investigates how disabled people adapt existing virtual assistants to stay independent, thereby improving their quality of life and meeting their complex social care needs. The project includes examining how these new technologies are impacting the social care workforce.

This project is a ServCollab project because: 1) It seeks to help disabled people meet their complex social care needs. 2) The five collaborating researchers are from different disciplines (social psychology, information and computer science, sociology of work, and service management). 3) The research team also collaborates with a social enterprise with significant experience in social care services. 4) Moreover, as described below, research study participants will collaborate with the research team, too. It is further planned to train disabled people and care workers how to use key social science methods and research skills. For example, providing them with training in interview methods that will allow them to conduct semi-structured interviews with pairs of disabled people and care workers. Participants will also be provided with equipment and training on how to make recordings for interactional video analysis. Finally, 
participants will also collaborate with each other to help each other learn how to best use technology (via personal meetings and/or sharing experience in online forums).

To enable collaboration between all parties (i.e., researchers, disabled people, and carers) from the beginning, this ServCollab project will use an action research methodology (as described in the Tools for Serving Humanity section). It especially means that disabled people and carers will not be passive study participants but will be active "co-investigators" by getting involved in all aspects of the research project. It also means that they will have a say at every stage of the research process, starting with the design of the study, followed by data-collection and analysis, and concluding with the dissemination of the research findings. This project is currently at the design stage. It is envisaged that qualitative interviews and interactional video/conversation analysis will be used to understand how disabled people and their carers are using virtual assistants to improve their quality of life. However, due to the collaborative nature of the study, the exact research design and the specific research questions will be co-created with all participants. The research team is currently contacting several disabled people-led organizations, covering a range of impairments, to find study collaborators. It is planned that research findings will be shared with several organizations, including parliamentary groups on social care, disability, and AI. It is also envisioned that one way of disseminating the project results will include creating a website for sharing tips and tricks among disabled people, which could support valuable collaborative learning among the disabled community.

\section{Possible Future ServCollab Projects}

There are many possible future ServCollab projects. In the service inclusion area, one of the greatest service inclusion problems is the widespread neglect and exclusion of women and girls in human service systems throughout the world. Since women and girls represent 
approximately half of the human species, ServCollab is especially eager for service inclusion projects on behalf of women and girls.

A second possible project area is building service language. Language enables human interactions. Academic disciplines create their own technical languages that can be impediments to innovation and progress. To accelerate human wellbeing, new service knowledge needs to be openly communicated and shared with the many academic disciplines that are human facing (such as the humanities, social sciences, the arts, criminal justice, education, health care, industrial engineering, and social work). Gorman (2010) argues for trading zones between disciplines that are facilitated by a creole (simplified common language). The challenge is to create a common language regarding service that improves communication across the developing service research community. ServCollab encourages projects that seek to create service language that researchers and human populations can use to understand and improve human wellbeing for all.

Third, a profoundly important possible ServCollab project area is climate change. Human life depends on Planet Earth, so the service research field needs to respond by encouraging projects that balance serving human needs now with serving the needs of future generations by protecting the fragile service ecosystem of Planet Earth. Finally, ServCollab seeks projects that describe the characteristics of a healthy human ecosystem on Planet Earth. An early effort at such an effort proposed broadening the concept of service from human-to-human to a tripartite perspective of human-to-nature-to-human (Shirahada and Fisk, 2011). The tripartite logic transforms the concept of service from human centric value co-creation to tripartite value cocreation based on maintaining and enhancing human wellbeing, while maintaining and enhancing environmental sustainability (Shirahada and Fisk, 2011). 


\section{A Call to Collaborate on Future ServCollab Projects}

ServCollab seeks to build a global service research network robust enough to work on big service system problems that seek to elevate the Human Experience (HX). This will require building operational capacity by recruiting, training, and collaborating with scholars from within the service research field and with scholars from other disciplines that are human facing. Funding will be sought for these major service system projects from foundations, government agencies, and universities. ServCollab will also seek to create new service research tools and new measurement systems for these large-scale service system problems. Most importantly, ServCollab will identify project topics, assemble research teams, and support their efforts to collaboratively design or redesign solutions to human service system problems. To succeed, these efforts will require breakthrough collaborations that are truly innovative (Shneiderman, 2016). Innovation is the lifeblood of human progress. As Lusch and Vargo (2014) note "...the more we innovate the more the innovation frontier expands.” (p. 205). Transformative collaboration (Fisk et al., 2019) that accelerates human progress is possible.

To get involved with ServCollab, interested service scholars can join ServCollab via our website - https://www.servcollab.org/. ServCollab seeks to be a hub of service research collaboration on behalf of humanity. There are many ways to participate: 1) You can learn more about service research collaboration opportunities. 2) You can suggest a service research project. 3) You can recruit other service research collaborators to join ServCollab.

In creating ServCollab, we are well aware of the progressive efforts of many organizations that may become important allies in collaborative pursuit of a better future for our species. The American Marketing Association Service Special Interest Group (SERVSIG) is the 
primary organization serving the service research community. Hence, SERVSIG members will be encouraged to participate in ServCollab research projects. In addition, there are numerous service research conferences that might encourage ServCollab projects. These include wellknown service research conferences: Frontiers in Service Conference, The LaLonde Conference, the QUIS Conference, and the SERVSIG Research Conference. There are numerous university service research centers that may be collaborators including: the Arizona State University Center for Service Leadership, USA; the Bocconi University Center for Research on Marketing and Services, Italy; the Cornell University Center for Hospitality Research, USA; the Florida Atlantic University Center for Service Marketing \& Management, USA; the Hanken School of Economics Centre for Relationship Marketing and Service Management, Finland; the Karlstad University CTF - Service Research Center, Sweden; the Katholische Universität (KU) Research Institute for Business and Economics in Service of Humanity, Germany; the Loughborough University Centre for Service Management, UK; the Maastricht University Service Science Factory, the Netherlands; the Singapore Management University Institute for Service Excellence, Singapore; the University of Edinburgh Centre for Service Excellence, UK; and the University of Maryland Center for Excellence in Service, USA. In addition, there is a new organization called the Responsible Research in Business and Management (RRBM) "dedicated to inspiring, encouraging, and supporting credible and useful research in the business and management disciplines. (RRBM, 2019). While RRBM focuses on improving business disciplines, like ServCollab, it shares an interest in improving human society through research.

\section{Conclusion}


This article began by explaining why ServCollab takes a broader perspective for serving humanity by seeking to elevate the Human Experience (HX). Second, standards of justice for serving humanity were proposed. Third, transformative service research's role in raising the service research community's aspirations for serving humanity was described. Fourth, service design and community action research were explored as powerful research approaches for serving humanity. Fifth, ServCollab's first projects were summarized. Finally, the article discussed a call to collaborate on future ServCollab efforts.

Service research has evolved to study the profound role that service plays in human lives. In doing so, the service research field is moving from the perimeter of human experience to the center of human experience. To elevate HX, service researchers need to spread the news that service is central to the human experience.

Transformative Service Research (TSR) has become an influential service research subtopic that challenges service researchers to aspire to conducting research that improves human wellbeing through service (Anderson et al., 2013). Improving wellbeing through transformative service is a major service research priority (Ostrom et al., 2015). ServCollab seeks to make TSR a major service research practice.

The first two decades of the $21^{\text {st }}$ century were remarkably turbulent. A large number of democracies have experienced high levels of economic inequality, extreme political polarization, and structural fragility that threatens their future. Meanwhile Planet Earth is experiencing an unprecedented human refugee crisis and an accelerating climate change crisis. In these troubled and turbulent times, the worst human instincts of fear and hatred are causing conflict and competition between nations and peoples. These combative instincts led to two world wars in the twentieth century. The nuclear arms race that occurred after World War II was a dangerous relic 
of those times. Before it is too late, our species needs to find a path to transformative collaboration that protects our species and our planet.

To improve wellbeing for all, ServCollab will focus on transformative service research collaborations that seek to reduce global service system injustices and elevate human experience. Through our research, we seek to help our species find the means to live in harmony with each other and with the earth. The only way to make Planet Earth a healthy ecosystem again is to find the means to rise above our primitive instincts and create collaborative solutions to human needs. The human service systems we live in should serve all human needs and they should protect the environment for future generations. Please help us serve humanity through service research collaborations that reduce human suffering and improve human wellbeing. 


\section{References}

Abbott, P. and Wallace, C. (2012), "Social Quality: A way to measure the quality of society", Social Indicators Research, Vol. 108 Vol. 1, pp. 153-167.

Acemoglu, D. and Robinson, J.A. (2012), Why Nations Fail: The Origins of Power, Prosperity and Poverty, Crown Publishers, New York.

Adams, J.S. (1965), "Inequity in Social Change", in L. Berkowitz (ed.). Advances in Experimental Social Psychology, Vol. 2. Academic Press, New York, pp. 267-299.

Akaka, M.A. and Vargo, S.L. (2015), "Extending the context of service: from encounters to ecosystems", Journal of Services Marketing, Vol. 29 No. 6/7, pp. 453-462.

Al-Heeti, A. (2019), “Amazon has sold more than 100 million Alexa devices”, available at: https://www.cnet.com/news/amazon-has-sold-more-than-100-million-alexa-devices/ (accessed 12 October 2019).

Alkire, L., Mooney, C., Gur, F., Kabadayi, S., Renko, M., and Vink, J. (2019), “Transformative service research, service design, and social entrepreneurship: An interdisciplinary framework advancing wellbeing and social impact", Journal of Service Management, Vol 31 No. 1, pp. 24-50.

Anderson, L., Ostrom, A.L., Corus, C., Fisk, R.P., Gallan, A.S., Giraldo, M., Mende, M., Mulder, M., Rayburn, S.W., Rosenbaum, M.S., Shirahada, K. and Williams, J.D. (2013), "Transformative Service Research: An Agenda for the Future", Journal of Business Research, Vol. 66, pp. 1203-1210.

Anderson, L. and Ostrom, A. (2015), “Transformative Service Research: Advancing our knowledge about service and well-being", Journal of Service Research, Vol. 18 No. 3, pp. 243-249. 
Anderson, L. and Ostrom, A. (2018), “Hoping for Hope: Tackling gnarly issues in Transformative Service Research, Keynote presentation at the Frontiers in Service Conference. Austin, Texas.

Angus, S.D. \& Newton, J. (2015), "Emergence of shared intentionality is coupled to the advance of cumulative culture", PLOS Computation Biology, Vol. 11 No. 10, pp. 1-12.

Barker, C. (2005), Cultural Studies: Theory and Practice. Sage, London.

Bitner, M.J., Booms, B.H. and Tetreault, M.S. (1990). The service encounter: diagnosing favorable and unfavorable incidents. Journal of Marketing, Vol. 54 No. 1, pp. 71-84.

Blau, P.M. (1964), Exchange and Power in Social Life. Wiley, New York.

Blocker, C.P. and Barrios, A. (2015), "The transformative value of a service experience", Journal of Service Research, Vol. 18 No. 3, pp. 265-283.

Blodgett, J. G., Hill, D. J., and Tax, S. S. (1997), "The effects of distributive, procedural, and interactional justice on postcomplaint behavior", Journal of Retailing, Vol. 73 No. 2, 185-210.

Boenigk, S., Fisk, R.P., Kabadayi, S., Alkire, L., Cheung, L., Corus, C., Finsterwalder, J., Kreimer, A.A., Luca, N., Omeira, M., Paul, P., Santos, M.F. \& Smidt, N. (2020), "Rethinking services and public policy: A transformative refugee service framework”, working paper.

Bone, S. A., Christensen, G. L., and Williams, J. D. (2014), "Rejected, shackled, and alone: The impact of systemic restricted choice on minority consumers' construction of self', Journal of Consumer Research, Vol. 41 No. 2, pp. 451-474.

Cipolla, C. and J. Reynoso (2017), "Service Design as a Sensemaking Activity: Insights from the LowIncome Communities in Latin America”, in D. Sangiorgi and A. Prendiville (eds.), Design for Service: Key Issues and Research Directions, Bloomsbury, London, pp. 147-161. 
Crocker, D. A. (2008), Ethics of Global Development: Agency, Capability, and Deliberative Democracy. Cambridge University Press: Cambridge, UK.

Cropanzano, R., Bowen, D.E. and Gilliland, S.W. (2007), "The Management of Organizational Justice", Academy of Management Perspectives, Vol. 21 No. 4, pp. 34-48.

Dennett, D.C. (1995), Darwin's dangerous idea: Evolution and the meanings of life, Simon \& Schuster, New York.

Deutsch, M. (1985), Distributive Justice. Yale University Press, New Haven, CT.

Dickson, T.J., Darcy, S., Johns, R. and Pentifallo, C. (2016), "Inclusive by design: Transformative services and sport-event accessibility", Service Industries Journal, Vol. 36 No. 11/12, pp. 532555.

Edgell, P., Stewart, E., Billups, S.C. and Larson, R. (2019), “The Stakes of Symbolic Boundaries", The Sociological Quarterly, (accessed 27 June 2019).

Fine, M. (2018a), Just research in contentious times: Widening the methodological imagination, Columbia University Teachers College Press, New York.

Fine, M. (2018b), Podcast interview with by Pengfei Zhao November 16, 2018. "Just research in contentious times: widening the methodological imagination", newbooksnetwork.com/michelle-fine-just-research-in-contentious-times-widening-themethodological-imagination-teachers-college-2018/. (accessed October 2, 2019).

Fisk, R.P. (2009), "A Customer Liberation Manifesto", Service Science, Vol. 1 No. 3, pp. 135-141.

Fisk, R.P. and S.J. Grove, (2010), The Evolution and Future of Service: Building and Broadening a Multidisciplinary Field in Handbook of Service Science, P.P. Maglio, C.A. Kieliszewski, and J.C. Spohrer, Editors, Springer: New York. pp. 643-663. 
Fisk, R.P., Anderson, L., Bowen, D.E., Gruber, T., Ostrom, A.L., Patrício, L., Reynoso, J. and Sebastiani, R. (2016), "Billions of Impoverished People Deserve to Be Better Served: A Call to Action for the Service Research Community", Journal of Service Management, Vol. 28 No. 1, pp. 43-55.

Fisk, R.P., Dean, A.M., Alkire (née Nasr), L., Joubert, A., Previte, J., Robertson, N. and Rosenbaum, M.S. (2018), "Design for service inclusion: creating inclusive service systems by 2050", Journal of Service Management, Vol. 29 No. 5, pp. 834-858.

Fisk, R., Fuessel, A., Laszlo, C., Struebi, P., Valera, A. and Weiss, C. (2019), "Systemic social innovation: Co-creating a future where humans and all life thrive", Humanistic Management Journal, Vol. 4 No. 2, pp. 191-214.

Friedman, K. (2003), "Theory Construction in Design Research: Criteria, Approaches and Methods." Design Studies, Vol. 24 No. 6, 507-522.

Giddens A. (1984), The constitution of society. Outline of a theory of structuration. Polity Press, Cambridge.

Goodman, D. (2013), “City Council votes to increase oversight of New York Police”, The New York Times, June 27, 2013. https://www.nytimes.com/2013/06/27/nyregion/new-yorkcity- council-votes-to-increase-oversight-of-police-dept.html. (accessed October 26 2019).

Gorman, M. (2010), Trading Zones and Interactional Expertise: Creating New Kinds of Collaboration (Inside Technology), MIT Press, Cambridge, MA.

Guishard, M.A. (2015), “Nepantla and Ubuntu ethics para nosotros: Beyond scrupulous adherence toward threshold perspectives of participatory/collaborative research ethics", Doctoral Dissertation, The Graduate and University Center, City University of New 
York, New York, NY. http://academicworks.cuny.edu/gc_etds/957 (accessed October 18, 2019).

Guishard, M.A., Halkovic, A., Galletta, A., and Li, P. (2018), “Toward epistemological ethics: centering communities and social justice in qualitative research", Forum Qualitative Sozialforschung / Forum: Qualitative Social Research, Vol. 19 No. 3. Available at: http://www.qualitative-research.net/index.php/fqs/article/view/3145/4312. (accessed October 15, 2019).

Hoy, M. B. (2018), “Alexa, Siri, Cortana, and more: an introduction to voice assistants", Medical Reference Services Quarterly, Vol. 37 No.1, pp. 81-88.

Kabadayi, S., Alkire, L., Broad, G., Livne-Tarandash, R., Wasieleski, D., and Puente, A. M. (2019), "Humanistic Management of Social Innovation in Service (SIS): An Interdisciplinary Framework", Humanistic Management Journal, Vol. 4 No.2, 159-185.

Lamont, M. and Molnár, V., (2002), “The Study of boundaries across social sciences”, Annual Review of Sociology, Vol. 28, pp.167-95.

Lamont, M., Pendergrass, S., and Pachucki, M. (2015), “Symbolic Boundaries”, International Encyclopedia of the Social \& Behavioral Sciences, Elsevier, Oxford, pp. 850-855.

Leventhal, G. S., Karuza, J., and Fry, W. R. (1980), "Beyond fairness: A theory of allocation preferences", Justice and Social Interaction, Vol. 3 No. 1, 167-218.

Lockwood D. (1992), Solidarity and schism: The problem of disorder in Durkheimian and Marxist sociology. Oxford University Press, Oxford and New York.

Lusch, R.F. and Vargo, S.L. (2014), Service-Dominant Logic: Premises, Perspectives, Possibilities, Cambridge University Press, New York. 
Maglio, P.P., Vargo, S.L., Caswell, N. and Spohrer, J. (2009), "The Service System Is the Basic Abstraction of Service Science", Information Systems E-Business Management, No. 7, pp. 395406.

Maslow, A. H. (1943), “A Theory of Human Motivation”, Psychological Review, January, pp. 370-396.

Meroni, A. and D. Sangiorgi, Eds. (2011), Design for Services. Design for Social Responsibility Series. Gower, Surrey.

Merriam-Webster.com (2020), “Service”, https://www.merriam-webster.com/dictionary/service, [Accessed on February 23, 2020].

Messick, D.M. and Cook, K.S. (1983). "Psychological and Sociological Perspectives on Distributive Justice: Convergent, Divergent and Parallel Lines", in D.M. Messick and K.S. Cook (eds.). Equity Theory: Psychological and Sociological Perspectives. Praeger, New York, pp. 1-13.

Morris Justice: A Public Science Project. Morrisjustic.org. (accessed October 5, 2019).

Onasch, E. A. (2017), "Lessons on the boundaries of belonging: racialization and symbolic boundary drawing in the French Civic Integration Program", Social Problems, Vol. 64 No. 4, pp. 577-593.

Ostrom, A.L., Bitner, M.J., Brown, S.W., Burkhard, K.A., Goul, M., Smith-Daniels, V., Demirkan, H. and Rabinovich, E. (2010), "Moving Forward and Making a Difference: Research Priorities for the Science of Service", Journal of Service Research, Vol. 13 No. 1, pp. 4-36.

Ostrom, A.L., Parasuraman, A., Bowen, D.E., Patrício, L. and Voss, C.A. (2015), "Service research priorities in a rapidly changing context", Journal of Service Research, Vol. 18 No. 2, pp. 127159.

Ozanne, J. and Anderson, L. (2010), “Community Health Action Research”, Journal of Public Policy and Marketing, Vol. 29 No. 1, pp. 123-137. 
Parker, G., Alstyne, M.W.V. and Choudary, S.P. (2016), Platform Revolution: How Networked Markets Are Transforming the Economy--And How to Make Them Work for You, W. W. Norton \& Company, NY.

Patrício, L., Fisk, R.P. and Cunha, J.F. (2008), "Designing Multi-Interface Service Experiences: the Service Experience Blueprint", Journal of Service Research, Vol. 10 No. 4, pp. 318-334.

Patrício, L., Fisk, R.P., Cunha, J.F. and Constantine, L. (2011), "Multilevel Service Design: From Customer Value Constellation to Service Experience Blueprinting", Journal of Service Research, Vol. 14, No. 2, pp. 180-200.

Patrício, L., Gustafsson, A. and Fisk, R. (2018a), "Upframing service design and innovation for research impact", Journal of Service Research, Vol. 21 No. 1, pp. 3-16.

Patrício, L., Pinho, N., Teixeira, J.G. and Fisk, R.P. (2018b), "Service design for value networks: Enabling value cocreation interactions in healthcare", Service Science, Vol. 10 No. 1, pp. 76-97.

Patrício, L., Teixeira, J. G. and Vink J. (2019). "A service design approach to healthcare innovation: from decision-making to sense-making and institutional change." Academy of Marketing Science Review, Vol. 9 No. 1/2, 115-120.

Rawls, J. (1999), A theory of justice: Revised edition, Harvard University Press, Cambridge, Massachusetts.

Robeyns, I. (2016), "The Capability Approach", The Stanford Encyclopedia of Philosophy, Edward N. Zalta (ed.). Stanford University, Palo Alto.

Rosenbaum, M.S., Corus, C., Ostrom, A.L., Anderson, L., Fisk, R.P., Gallan, A.S., Giraldo, M., Mende, M., Mulder, M., Rayburn, S.W., Shirahada, K. and Williams, J.D. (2011), "Conceptualisation and Aspirations of Transformative Service Research", Journal of Research for Consumers, No. 19, pp. 1-6. 
RRBM (2019), “A vision of responsible research in business and management”, available at: https://rrbm.network (accessed 27 October 2019).

Sanders, E. (2008), "An Evolving Map of Design Practice and Design Research", Interactions, Vol. 15 No. 6, pp. 13-17.

Sangiorgi, D. (2010), "Transformative Services and Transformation Design", International Journal of Design, Vol. 5 No. 1, pp. 29-40.

Sangiorgi, D., Lima, F., Patrício, L., Joly M. P., and Favini, C. (2019), “A Human-Centred, Multidisciplinary, and Transformative Approach to Service Science: A Service Design Perspective”, in P.P. Maglio, C.A. Kieliszewski, J.C. Spohrer et al.(eds.), Handbook of Service Science, Cham, Switzerland, pp. 147-181.

Schneider, B. and Bowen, D.E. (1995), Winning the Service Game, Harvard Business School Press, Boston, MA.

Sen, A. K. (1982), "Equality of what?", in A. K. Sen (Ed.), Choice, Welfare and Measurement, Blackwell, Oxford.

Shirahada, K. and Fisk, R.P. (2011), "Broadening the concept of service: A tripartite value co-creation perspective for service sustainability", paper presented at Advances in Service Quality, Innovation, and Excellence, Proceedings of QUIS12, Ithaca, New York.

Shneiderman, B. (2016), The New ABCs of Research: Achieving Breakthrough Collaborations, Oxford University Press, Oxford, UK.

Simon, H. A. (1969), The Sciences of the Artificial. MIT Press, Cambridge, MA.

Stringer, E.T. (1999), Action Research, Sage Publications, Thousand Oaks, CA. 
Teixeira, J.G., Patrício, L., Huang, K.-H., Fisk, R.P., Nóbrega, L. and Constantine, L. (2017), "The MINDS Method: Integrating Management and Interaction Design Perspectives for Service Design", Journal of Service Research, Vol. 20 No. 3, pp. 240-258.

Teixeira, J. G., Patrício, L. and Tuunanen, T. (2019), "Advancing service design research with design science research," Journal of Service Management, Vol. 30 No. 5, pp. 577-592.

Thomas, W. H. and Blanchard, J. M. (2009), “Moving Beyond Place: Aging in Community”, Journal of the American Society on Aging, Vol 33, No. 2, 12-17.

Tomasello, M., Melis, A.P., Tennie, C., Wyman, E., and Herrmann, E. (2012), “Two key steps in the evolution of human cooperation”, Current Anthropology, Vol. 53 No. 6, pp. 673-692.

Tuck, E. (2009), “Suspending damage: A letter to communities”, Harvard Educational Review, Vol. 79 No. 3, pp. 409-428.

United Nations (2016), About the Sustainable Development Goals, United Nations, viewed September $22,2019$.

Van Aken, J.E. (2004), "Management Research Based on the Paradigm of the Design Sciences: The Quest for Field-Tested and Grounded Technological Rules", Journal of Management Studies, Vol. 41 No. 2, pp. 219-246.

van der Merwe, A., and Hunt, X. (2019), “Secondary trauma among trauma researchers: Lessons from the field", Psychological Trauma: Theory, Research, Practice, and Policy, Vol. 11 No. 1, pp. 10-18.

Vink, J., Edvardsson, B., Wetter-Edman, K. and Tronvoll, B. (2019), "Reshaping Mental Models Enabling Innovation through Service Design", Journal of Service Management, Vol. 30 No. 1, pp. $75-104$. 
Von Koskull, C. and Anderson, L. (2018), "Ethnodrama: Engaged pathway to relevance and Impact", Presented at the 2018 Frontiers in Service Conference, Austin, Texas.

Waygood, O., Friman, M., Olsson, L., and Mitra, M., (2019), Transport and Children's Wellbeing, Elsevier, Oxford.

Weis, L. and Fine, M. (2012), “Critical bifocality and circuits of privilege: expanding critical ethnographic theory and design", Harvard Educational Review, Vol. 82 No. 2, pp. 173201.

Wetter-Edman, K., Sangiorgi, D., Edvardsson, B., Holmlid, S., Grönroos, C. and Mattelmäki T. (2014), "Design for Value Co-Creation: Exploring Synergies Between Design for Service and Service Logic." Service Science, Vol. 6 No. 2, pp. 106-121.

Wetter-Edman, K., Vink J. and Blomkvist J. (2018), "Staging aesthetic disruption through design methods for service innovation", Design Studies, Vol. 55 No. 2, pp. 5-26.

Wilkinson, R.G. and Marmot, M.G. (2003), Social Determinants of Health: The Solid Facts: World Health Organization. World Health Organization, Geneva, Switzerland.

Wilson, R. and Kenny, C. (2018), "Robotics in social care", POSTnote (Parliamentary Office of Science and Technology), Vol. 591 December, pp. 1-7.

Wright, R. (2000), Nonzero: History, Evolution \& Human Cooperation, Little, Brown and Company, London, UK. 
Page 43 of 45

Journal of Service Management

$$
\begin{aligned}
& 1 \\
& 2 \\
& 3 \\
& 4 \\
& 5 \\
& 6 \\
& 7 \\
& 8 \\
& 9 \\
& 10 \\
& 11 \\
& 12 \\
& 13 \\
& 14 \\
& 15 \\
& 16 \\
& 17 \\
& 18 \\
& 19 \\
& 20 \\
& 21 \\
& 22 \\
& 23 \\
& 24 \\
& 25 \\
& 26 \\
& 27 \\
& 28 \\
& 29 \\
& 30 \\
& 31 \\
& 32 \\
& 33 \\
& 34 \\
& 35 \\
& 36 \\
& 37 \\
& 38 \\
& 39 \\
& 40 \\
& 41 \\
& 42 \\
& 43 \\
& 44 \\
& 45 \\
& 46 \\
& 47 \\
& 48 \\
& 49 \\
& 50 \\
& 51 \\
& 52 \\
& 53 \\
& 54 \\
& 55 \\
& 56 \\
& 57 \\
& 58 \\
& 59 \\
& 60
\end{aligned}
$$

http://mc.manuscriptcentral.com/josm 


\begin{tabular}{|l|l|l|l|l|}
\hline Names & Conflict & Competition & Cooperation & Collaboration \\
\hline Labels & War & Economic & Social & Just Society \\
\hline Games & Win - Lose & Win - Lose & Win - Win Mostly & Win - Win \\
\hline Outcomes & Victory/Suffering & Success/Suffering & Attenuated Wellbeing & $\begin{array}{l}\text { Transformative } \\
\text { Wellbeing }\end{array}$ \\
\hline Patterns & Dominance/Submission & Dominance/Submission & $\begin{array}{l}\text { Dominance/Submission } \\
\text { Possible }\end{array}$ & Mutual \\
\hline
\end{tabular}

Table 1: Categories of Human Interaction 
Figure 1: Metaphor of ServCollab as a Crane Elevating Human Experience

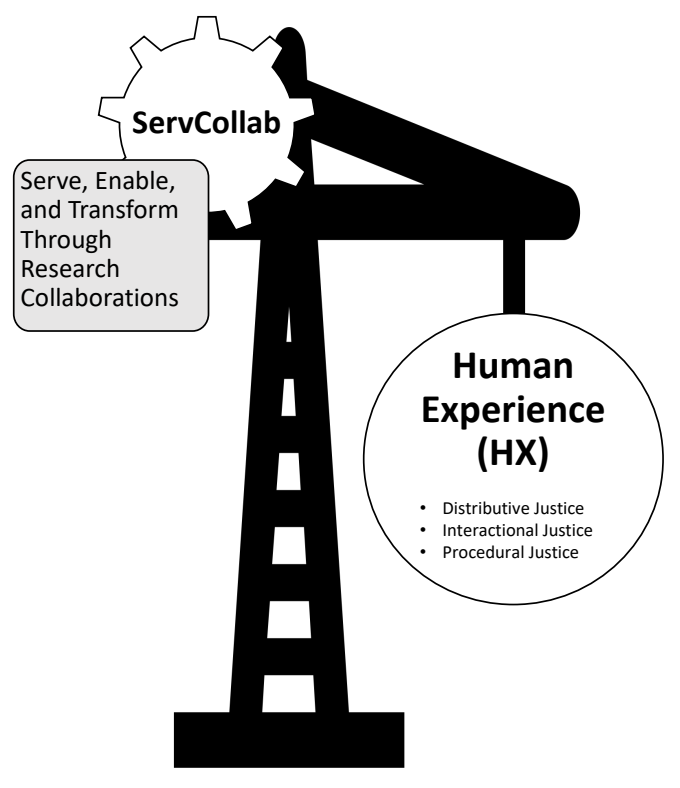

